\title{
Cs Leaching Behavior During Alteration Process of Calcium Silicate Hydrate and Potassium Alumino Silicate Hydrate
}

\author{
K. Kuroda ${ }^{1(凶)}$, K. Toda ${ }^{1}$, Y. Kobayashi ${ }^{1}$, T. Sato ${ }^{2}$, and T. Otake ${ }^{2}$ \\ ${ }^{1}$ Graduate School of Engineering, Hokkaido University, Hokkaido, Japan \\ k7927k@eis.hokudai.ac.jp \\ ${ }^{2}$ Faculty of Engineering, Hokkaido University, Hokkaido, Japan
}

\begin{abstract}
Zeolite, used to remove Cs from a contaminated water, would be solidified for the safety disposal. Recently, geopolymer is considered as a new binder for disposal. Geopolymer has an advantage that primary phases such as potassium almino silicate hydrate (K-A-S-H) may sorb radioactive nuclides. In this study, Cs adsorption, co-precipitation and desorption experiment were conducted, and C-S-H, which is primary phases of cement, were also employed for experiments for comparison. From these experiments, it is obtained that K-A$\mathrm{S}-\mathrm{H}$ has higher adsorption capacity of $\mathrm{Cs}$ than $\mathrm{C}-\mathrm{S}-\mathrm{H}$. Cs adsorption ratio and coprecipitation ratio by C-S-H were almost same. Cs is likely sorbed by C-S-H thoroughly via ion exchanging. The desorption experiment demonstrated that most Cs was desorbed from C-S-H while $90 \%$ of Cs remained in K-A-S-H. Therefore, K-A-S-H has a higher retention capacity than that of C-S-H. Consequently, geopolymer is considered to be a better material in terms of Cs storage.
\end{abstract}

Keywords: Geopolymer $\cdot \mathrm{K}-\mathrm{A}-\mathrm{S}-\mathrm{H} \cdot \mathrm{C}-\mathrm{S}-\mathrm{H} \cdot$ Radioactive waste

\section{Introduction}

After the accident at the Fukushima Daiichi Nuclear Power Station that occurred due to the The2011 off the Pacific coast of Tohoku Earthquake, contaminated water with radioactive nuclides such as cesium (Cs) have been continuously generated. Zeolite have been used for removing Cs from the contaminated water, and the spent zeolite are currently planned to be solidified for the safety storage and disposal. Recently, geopolymer is considered as a new binder for safety disposal of spent zeolite. Geopolymer has an advantage that primary phases such as potassium almino silicate hydrate (K-A-S-H) may have property for sorbing radioactive nuclides. However, there are few data about the adsorption behavior of Cs by K-A-S-H and the Cs leaching during their alteration.

\section{Methods and Approaches}

In this study, C-S-H, which is primary phases of cement, were also employed for experiments for comparison. In adsorption experiments, powder C-S-H and K-A-S-H were put into Cs-solution whose concentration is $1.0 \mathrm{mM}$ at $298 \mathrm{~K}$ for a week. And in 
co-precipitation experiment, the materials to synthesize C-S-H were put. K-A-S-H could not be conducted co-precipitation experiment because water react with materials during synthesize. The solid sample after adsorption experiment were investigated in batch test and flow-through test as desorption experiment of Cs. The period of batch test is 4months and that of flow-through test is a month. And deionized water was used in both of them.

\section{Results and Discussion}

The adsorption ratio by $\mathrm{K}-\mathrm{A}-\mathrm{S}-\mathrm{H}$ is $92 \%$, while the adsorption ratio by $\mathrm{C}-\mathrm{S}-\mathrm{H}$ is $29 \%$. The reason of this is considered that the size of sorption site is based on ionic radius of $\mathrm{K}$ or $\mathrm{Ca}$, and that of $\mathrm{Cs}$ is similar to $\mathrm{K}$ than $\mathrm{Ca}$. The adsorption ratio and co-precipitation ratio by $\mathrm{C}-\mathrm{S}-\mathrm{H}$ is almost same. $\mathrm{Cs}$ is likely sorbed by $\mathrm{C}-\mathrm{S}-\mathrm{H}$ thoroughly via ion exchanging, so it may be easy to sorb even after generation. In batch test as desorption experiment, the reaction between solid and water phase became equilibrium in 1month, and $\mathrm{Cs}$ concentration were almost stable after that. The desorption ratio from C-S-H was around $20 \%$ and from $\mathrm{K}-\mathrm{A}-\mathrm{S}-\mathrm{H}$ was around $2 \%$. But in flow through test, C-S-H desorb almost all of $\mathrm{Cs}$ in a day. It is considered that $\mathrm{Cs}$ sorption by $\mathrm{C}-\mathrm{S}-\mathrm{H}$ is ion exchange, so it is easy to leach by ion exchange too. On the other hand, The desorption ratio from K-A$\mathrm{S}-\mathrm{H}$ was almost $1 \%$ per day until 1 month had past. Cs/Si ratio in each day was constant, and $\mathrm{Si}$ concentration is considered to depend on the dissolution amount of K-A-S-H. It is considered that $\mathrm{Cs}$ concentration also depended on that. From these results, it can be said that K-A-S-H has higher property to prevent desorption of Cs than C-S-H.

\section{Conclusions}

Consequently, K-A-S-H has higher retention capacity than that of C-S-H. These results show that geopolymer whose matrix is composed of $\mathrm{K}-\mathrm{A}-\mathrm{S}-\mathrm{H}$ is considered to be better in terms of Cs storage.

Acknowledgements. This work was supported by MEXT 8杼の認可番号, Long-term performance of cement disposal systems for synthetic zeolites and titanates arising from reprocessing of contaminated water.

Open Access This chapter is licensed under the terms of the Creative Commons Attribution 4.0 International License (http://creativecommons.org/licenses/by/4.0/), which permits use, sharing, adaptation, distribution and reproduction in any medium or format, as long as you give appropriate credit to the original author(s) and the source, provide a link to the Creative Commons license and indicate if changes were made.

The images or other third party material in this chapter are included in the chapter's Creative Commons license, unless indicated otherwise in a credit line to the material. If material is not included in the chapter's Creative Commons license and your intended use is not permitted by statutory regulation or exceeds the permitted use, you will need to obtain permission directly from the copyright holder.

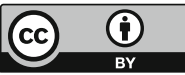

